Revista Brasileira de Farmacognosia Brazilian Journal of Pharmacognosy 23(1): 86-93, Jan./Feb. 2013

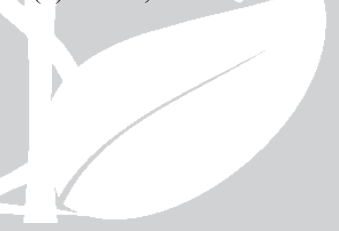

Article

Received 7 Feb 2012

Accepted 8 Aug 2012

Available online 6 Sep 2012

Keywords:

breast adenocarcinoma cells

functional ingredient

LC-MS/MS

nitric oxide

soybean isoflavones

ISSN 0102-695X

DOI: $10.1590 / \mathrm{S} 0102-695 \mathrm{X} 2012005000101$

\section{Soybean extracts enriched with free isoflavones promote nitric oxide synthesis and affect the proliferation of breast adenocarcinoma cells}

\author{
Pablo G. Ferreira, ${ }^{1}$ Lucas Frungillo, ${ }^{1}$ Veridiana V. Rosso, ${ }^{\#, 2}$ Daisy \\ Machado, ${ }^{3}$ Adriana Z. Mercadante, ${ }^{2}$ Carmen V. Ferreira, ${ }^{3}$ Ione \\ Salgado ${ }^{*}$,
}

\author{
${ }^{1}$ Departamento de Biologia Vegetal, Instituto de Biologia, Universidade Estadual \\ de Campinas, Brazil, \\ ${ }^{2}$ Departamento de Ciências de Alimentos, Faculdade de Engenharia de Alimentos, \\ Universidade Estadual de Campinas, Brazil, \\ ${ }^{3}$ Departamento de Bioquímica, Instituto de Biologia, Universidade Estadual de \\ Campinas, Brazil.
}

\begin{abstract}
Although soybean isoflavones naturally accumulate in their conjugated forms, the beneficial effects on human health of soybean-containing foods have been credited to their aglycone forms. In the present study we analyzed the effects of a chemical agent, sodium nitroprusside (SNP), in eliciting the exudation of nonconjugated isoflavones from intact soybean seeds, embrionary axes and cotyledons. The isoflavones in the exudates were determined by high performance liquid chromatography and mass spectrometry. The effect of the exudates on the emission of nitric oxide (NO) and on the proliferation of breast carcinoma cells (MCF-7) was also evaluated. SNP elicitation increased the production of the aglycone forms dose- and time-dependently. Exudates of embrionary axes and cotyledons stimulated NO emission and showed biphasic effects on viability of MCF-7 cells. At lower concentrations both extracts presented proliferative effects (10-25\%), and at higher concentrations inhibited (15\%) cell proliferation. The biphasic effect might be due to the action of isoflavone aglycones in activating estrogen receptors which in turn stimulate the production of NO. Overall, the results suggest that soybean extracts enriched in isoflavone aglycones by elicitation with SNP could be exploited as a functional ingredient in the food industry.
\end{abstract}

\section{Introduction}

The potential of functional foods to provide health benefits has been increasingly recognized. Epidemiological evidence has supported the proposal that isoflavones are the agents in soybean which account for the apparent association between the increase in soy consumption and the reduction in the incidence of various chronic diseases (Adlercreutz \& Mazur, 1997; Brouns, 2002). Several reports have described the positive effect of isoflavones on the prevention of hormone-dependent cancers, cardiovascular diseases, osteoporosis, adverse menopausal manifestations and accelerated cognitive decline (Pilšáková et al., 2010). Other studies have demonstrated a significant correlation between the consumption of isoflavonoid-rich foods by people in East Asia and a lower incidence of breast, prostate and large intestine carcinomas and cardiovascular disease, the so- called "diseases of western countries" (Adlercreutz \& Mazur, 1997).

Isoflavones are found as aglycones, $\beta$-glucosides and $\beta$-glucosides conjugated with malonyl and acetyl acids in nature. Although predominantly found in their conjugated forms (Liu, 1997), several evidences indicate that the free forms of soybean-derived isoflavones (the aglycones daidzein, glycitein and genistein) exhibit the highest biological activities (Brown \& Setchell, 2001). These activities have been attributed to their antioxidant action (Yen \& Lai, 2003) and structural similarity to the estradiol hormone (Pilšáková et al., 2010). There are claims that, acting as estradiol, isoflavones aglycones may modulate immunological responses, cancer proliferation and prevent cardiovascular diseases and osteoporosis (Messina \& Messina, 1991; Brouns, 2002; Taku et al., 2011). At least part of these effects is due to nitric oxide synthase (NOS) modulation by estradiol 
(Townsend et al., 2011). In cancer, at low concentrations, $\mathrm{NO}$ is proangiogenic and may promote tumor growth; however, at higher concentrations, NO can be cytostatic and cytotoxic, thus inhibiting tumor growth (Jenkins et al., 1995).

Despite the controversial data concerning the bioavailability of isoflavones, it is accepted that only aglycones forms are absorbed in the stomach (Piskula et al., 1999), and are absorbed faster and in greater amounts than their glucoside forms in the intestine (Izumi et al., 2000). In fact, isoflavone absorption was shown to require initial hydrolysis by intestinal $\beta$-glucosidases (Setchell et al., 2002). These observations suggest that biotechnological and biochemical processes that would induce the production of aglycones may provide both nutritional and economic benefits in diseases prevention.

Soybean isoflavones are synthesized as a branch of the phenylpropanoid pathway, a secondary biosynthetic route in plants that can be activated in response to a variety of biotic and abiotic stresses (Dixon et al., 2002). Nitric oxide has been identified as a key activator of this pathway by inducing transcriptional activation of genes encoding key enzymes in this route, such as phenylalanine ammonia lyase (PAL) and chalcone synthase (Delledonne et al., 1998). In soybean cotyledons the NO donor sodium nitroprusside (SNP) was shown to induce large accumulation of free isoflavones (Modolo et al., 2002). This response was suggested to result from the stimulatory effect of SNP on the activity of PAL and, additionally, on the $\mathrm{B}$-glicosidases, resulting in the release of pre-formed isoflavone conjugates (Kretzchmar et al., 2009). Taking into account these previous observations, in this study we present an improved technique to increase the yield of free isoflavones in soybean seeds using the NO donor molecule SNP, and evaluate the effects of the exudates produced in the proliferation of breast adenocarcinoma cells via NO production.

\section{Material and Methods}

\section{Plant material}

Soybean seeds [Glycine max (L.) Merril cv. IAC-18] were provided by Dr. Nelson R. Braga (Instituto Agronômico de Campinas, Campinas, São Paulo, Brazil) and kept at $4{ }^{\circ} \mathrm{C}$ until analysis.

\section{Elicitation assay and exudates preparation}

Soybean seeds were sterilized with sodium hypochlorite $0.3 \%$, seed coats were removed and detached embrionary axes or cotyledons (50 units/10 $\mathrm{mL}$ ) were treated with an aqueous solution of sodium nitroprusside (SNP) at several concentrations and for different periods of time, as indicated in the figure legends. After the elicitation time, the samples were filtered and the exudate mixed with $10 \mathrm{~mL}$ methanol $80 \%$. They were then extracted for $20 \mathrm{~min}$ on a rotary mixer model NT150 (Nova Técnica, Piracicaba, Brazil), dried, solubilized in $500 \mu \mathrm{L}$ of methanol/formic acid $5 \%(1: 1)$ and filtered through a $0.22 \mu \mathrm{m}$ Millipore membrane (Billerica, MA) prior to HPLC analysis.

\section{Determination of conjugated and aglycone isoflavones}

Analysis was carried out as previously described by Lin \& Harnly (2007) in a HPLC model LC-20AD (Shimadzu, Kyoto, Japan) equipped with quaternary pumps, an on-line degasser, and an injection valve (Rheodyne LCC, Rohnert Park, USA) with a $20 \mu \mathrm{L}$ loop. The equipment included, connected in series, a photodiode array detector (DAD) SPDM20A (Shimadzu) and a mass spectrometer with an ion-trap analyzer (MS/MS) Esquire 4000 (Bruker Daltonics, Bremem, Germany) and an electron spray ESI ionization source. The isoflavones were identified according to Lin \& Harnly (2007) and quantified using external calibration curves for daidzein and genistein obtained from Sigma-Aldrich Corp. (St. Louis, MO) and glycitein and their $\beta$-glucosides (daidzin, genistin and glycitin) from LC Labs (Woburn, MA). The 6"-Omalonyl- $\beta$-glucosides were quantified using the curve of the corresponding $\beta$-glucosides.

\section{MCF-7 and $3 T 3$ cell culture}

Human breast adenocarcinoma MCF-7, obtained from American Type Culture Collection (Manassas, USA), and Mouse embryo fibroblast 3T3, from National Institutes of Health (Bethesda, MD), cells were cultured in RPMI-1640 and DMEM medium, respectively, supplemented with FSB 10\% and gentamicin $50 \mu \mathrm{g} . \mathrm{mL}-1$ in a humidified atmosphere containing $\mathrm{CO}_{2} 5 \%$, according to specification of American Type Culture Collection. To assess the cell viability, $10 \times 10^{3}$ cells were seeded in 96 well plates, and after 24 or $72 \mathrm{~h}$ of treatment with different concentrations of exudates 3-(4,5-dimethylthiazol-2yl)-2,5-diphenyltetrazolium bromide (MTT) reduction, neutral red uptaken and nucleic acid content assays were performed as described in vitro cell viability assays section. For treatments, dry aliquots of exudates were solubilized in DMSO $100 \%$ and resuspended in culture medium ( 250 to $1000 \mu \mathrm{g} / \mathrm{mL}$ ). Aliquots of 100 $\mu \mathrm{L}$ of these solutions were applied to each well plate containing $10 \times 10^{3}$ cells. In all treatments DMSO concentration was kept at $0.25 \%$. 
In vitro cell viability assays

\section{MTT reduction}

Medium containing isoflavones was removed and $0.2 \mathrm{ml}$ of MTT solution $(0.5 \mathrm{mg}$ of $\mathrm{MTT} / \mathrm{mL}$ of culture medium) was added to each well. After incubation for $4 \mathrm{~h}$ at $37^{\circ} \mathrm{C}$, the medium was removed and intracellular formazan was released by solubilization in $0.2 \mathrm{~mL}$ of ethanol. Plate was shaken for $5 \mathrm{~min}$ on a plate shaker prior to measuring the absorbance at 570 nm (Mosmann, 1983).

\section{Neutral red uptake}

After $4 \mathrm{~h}$ incubation with serum-free medium containing $50 \mu \mathrm{g}$ of neutral $\mathrm{red} / \mathrm{mL}$ the cells were washed quickly with PBS and then $0.1 \mathrm{~mL}$ of a solution of $1 \%(\mathrm{v} / \mathrm{v})$ acetic acid: $50 \%(\mathrm{v} / \mathrm{v})$ ethanol was added to each well to extract the dye. After shaking for $10 \mathrm{~min}$ on a plate shaker the absorbance was read at $540 \mathrm{~nm}$ (Borenfreund \& Borrero, 1984).

\section{Nucleic acid content}

Cell monolayer was solubilized with $1 \mathrm{~mL}$ of $0.5 \mathrm{M} \mathrm{NaOH}$ at $37^{\circ} \mathrm{C}$ for $1 \mathrm{~h}$ afterwards the absorbance of the solution in each well was measured at $260 \mathrm{~nm}$ and the results expressed as a percentage of the control $\mathrm{A}_{260}$ (Cingi et al., 1991).

\section{Cell NO emission}

NO emission was determined using the DAF-2 fluorescent probe, as described by Hamuro et al. (2002). Briefly, the cells submitted to treatments were incubated in culture medium containing DAF-2 $2.5 \mu \mathrm{mol}^{-\mathrm{L}^{-1}}$ for $1 \mathrm{~h}$ at $37^{\circ} \mathrm{C}$. Culture medium was then collected and the fluorescence measured in a F-450 spectrofluorometer (Hitachi Instrument Co., Tokyo, Japan) at wavelengths of excitation at $488 \mathrm{~nm}$ and of emission at $530 \mathrm{~nm}$. When indicated, L-NAME $1 \mathrm{mmol} . \mathrm{L}^{-1}$ was added to culture medium to prevent NO production by NOS (Baylis et al., 1995).

\section{Statistical analysis}

Comparison of means was performed by two-way analysis of variance (ANOVA) followed by Tukey's test on Bioestat 5.0 software (Instituto de Desenvolvimento Sustentável Mamirauá, Tefé, Brazil).

\section{Results and Discussion}

Enriching the content of free isoflavones in soybean extracts

Given the well-established pharmacotherapeutic activity of free isoflavones, a methodology that is simple and efficient for the production of these compounds could be a great tool for the development of new products of commercial interest. To increase the proportion of the aglycone forms of isoflavones, soybean seeds were treated with the inducing agent sodium nitroprusside (SNP) which was previously proven to be very effective in activating the production of free isoflavones in cotyledons of soybean seedlings (Modolo et al., 2002; Kretzschmar et al., 2009). The
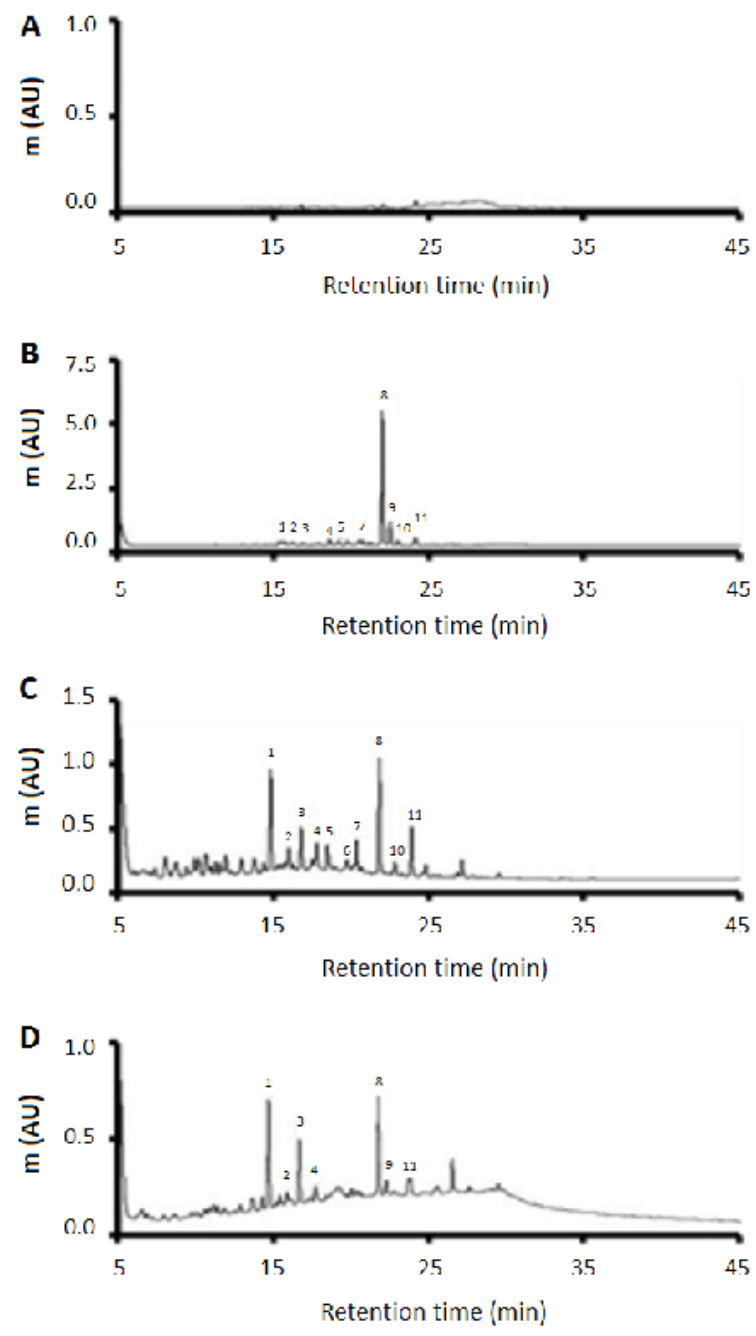

Figure 1. Chromatographic profile of isoflavones present in exudates of soybean seeds after treatment with $10 \mathrm{mM}$ sodium nitroprusside (SNP) for $15 \mathrm{~h}$. Extract of (A) untreated seeds and treated (B) embrionary axes, (C) cotyledons and (d) seeds. The identification of the numbered compounds is shown in Table 1. 
efficacy of this treatment was then evaluated in intact and non-germinated seeds, as well as in their two main components (embrionary axis and cotyledon). To perform this evaluation, we compared the results of the identification and quantification by HPLC-DADMS of the main isoflavones produced. Figure 1 shows the chromatographic profile, and Table 1 shows the amounts of isoflavones identified in the exudates when intact soybean seeds, embrionary axes or cotyledons were treated with $10 \mathrm{mM} \mathrm{SNP}$ for $15 \mathrm{~h}$.

To increase the reliability of the isoflavone identification in the samples and to assist in the identification of compounds $\beta$-conjugated to sugars and acids, the peaks detected by HPLC were also subjected to tandem mass spectrometry analysis and the results were consistent with the previously reported fragmentation profile of soybean isoflavones (Cuyckens \& Claeys, 2004).

Figure 1 shows that after treatment with SNP, large amounts of isoflavones accumulated in the exudates of embrionary axes, cotyledons and seeds. The production of these compounds in the control was insignificant, thus eliminating the possibility that the imbibition of the seeds or their parts with water or the mechanical stress (shaking) on the tissues could account for the results observed. As shown in Table 1, the exudate of embrionary axes presented the best yield in terms of total isoflavone production $(682 \pm 59.7 \mu \mathrm{g}$ of isoflavone per $\mathrm{g}$ of dried exudate), when compared to that of cotyledons $\left(101 \pm 13.0 \mu \mathrm{g} \mathrm{g}^{-1}\right)$ and seeds $\left(33 \pm 2.1 \mu \mathrm{g} . \mathrm{g}^{-1}\right)$. Additionally, it is remarkable that the treatment induced the exudation of a high proportion of aglycone forms (daidzein, genistein and glycitein) and much lower amounts of the glycosylated- and malonylconjugated forms in all treatments.

Among the aglycone forms, daidzein was the isoflavone that accumulated at the highest levels (approximately $50 \%$ of the total aglycone forms) in the exudates of the three SNP-treated tissues. The best induction of genistein was obtained in the exudates of elicited embrionary axes $\left(32 \pm 3.5 \mu \mathrm{g}\right.$.g fresh exudate $\left.{ }^{-1}\right)$.

The kinetics of isoflavonoid production as a function of the elicitation time and SNP concentration were evaluated in the exudates of embrionary axes. The production of isoflavones increased with incubation time (Figure 2A) and SNP concentration (Figure 2B), and the largest amount of aglycones was accumulated after $20 \mathrm{~h}$ of treatment with $200 \mathrm{mmol} \cdot \mathrm{L}^{-1}$ of SNP. However, with this treatment there is an increase in the relative proportion of the conjugated forms, when compared with the samples treated with $100 \mathrm{mmol}^{-\mathrm{L}^{-1}}$ SNP (Figure 2C). As the relative levels of aglycones are important for our purpose, elicitation with 100 mmol. $\mathrm{L}^{-1} \mathrm{SNP}$ for $20 \mathrm{~h}$ produced the best response in terms of aglycone forms.

As observed with embrionary axes, the production of isoflavones was also stimulated as a function of SNP concentration and elicitation time in cotyledons. When cotyledons were exposed to 100 mmol. $\mathrm{L}^{-1} \mathrm{SNP}$ for $20 \mathrm{~h}$ total production of aglycones was $1,062 \pm 12 \mu \mathrm{g} . \mathrm{g}^{-1}$, where $44 \%$ corresponded to daidzein, $44 \%$ to genistein and $12 \%$ to glycitein, indicating that this treatment can be used for the production of large amounts of genistein. It is important to mention that the analysis by HPLC and mass spectrometry did not reveal the presence of SNP or any degradation product of the

Table 1. Chromatographic parameters and concentrations of isoflavones identified in exudates of soybean seeds, cotyledons and embrionary axes treated with $10 \mathrm{mM}$ sodium nitroprusside for $15 \mathrm{~h}$.

\begin{tabular}{|c|c|c|c|c|c|c|}
\hline \multirow{2}{*}{ Peak } & \multirow{2}{*}{ Compound } & \multirow{2}{*}{$\mathrm{R}_{\mathrm{t}}(\min )^{b}$} & \multirow{2}{*}{$\lambda_{\text {max }}(\mathrm{nm})^{c}$} & \multicolumn{3}{|c|}{ Concentration ( $\mu$ g.g dry weight $\left.{ }^{-1}\right)$} \\
\hline & & & & Embryo* & Cotyledon & Seed \\
\hline 1 & not identified & 13.2 & 279,308 & n.d. & n.d. & n.d. \\
\hline 2 & daidzin & 14.1 & 260,300 & $13 \pm 1.1^{\mathrm{a}}$ & $8 \pm 3.5^{\mathrm{b}}$ & $3 \pm 0.1^{\mathrm{c}}$ \\
\hline 3 & glycitin & 15.1 & 260,317 & $15 \pm 1.3^{\mathrm{a}}$ & $13 \pm 3.1^{\mathrm{a}}$ & $13 \pm 1.3^{\mathrm{a}}$ \\
\hline 4 & genistin & 16.3 & 260,330 & $10 \pm 1.7^{\mathrm{a}}$ & $5 \pm 0.4^{\mathrm{b}}$ & $3 \pm 0.1^{\mathrm{c}}$ \\
\hline 5 & malonyl-daidzin $^{a}$ & 17.4 & 260,300 & $60 \pm 1.5^{\mathrm{a}}$ & $1 \pm 0.1^{\mathrm{b}}$ & n.d. \\
\hline 6 & malonyl-glycitin $^{a}$ & 18.3 & 262,318 & $45 \pm 1.8^{\mathrm{a}}$ & $7 \pm 0.4^{b}$ & n.d. \\
\hline 7 & malonyl-genistin $^{a}$ & 19.2 & 261,330 & $54 \pm 0.8^{\mathrm{a}}$ & $6 \pm 0.3^{\mathrm{b}}$ & n.d. \\
\hline 8 & daidzein & 20.1 & 260,302 & $243 \pm 37^{\mathrm{a}}$ & $29 \pm 1.3^{\mathrm{b}}$ & $8 \pm 0.2^{\mathrm{c}}$ \\
\hline 9 & glycitein & 21.0 & 260,319 & $210 \pm 11^{\mathrm{a}}$ & $14 \pm 2.2^{\mathrm{b}}$ & $3 \pm 0.1^{\mathrm{c}}$ \\
\hline 10 & not identified & 21.7 & 288,335 & - & & \\
\hline 11 & genistein & 22.2 & 262,330 & $32 \pm 3.5^{\mathrm{a}}$ & $18 \pm 1.7^{\mathrm{b}}$ & $3 \pm 0.4^{\mathrm{c}}$ \\
\hline
\end{tabular}

aConcentrations were estimated using the calibration curves of compounds 2,3 and 4; n.d.: not detected; $\mathrm{R}$ : retention time; ${ }^{\mathrm{a}}$ Eluate in the $\mathrm{C} 18$ column in oven at $32{ }^{\circ} \mathrm{C}$; ${ }^{c}$ Linear gradient of methanol $/ 5 \%$ formic acid. *Embrionary axis. Data are in $\mu \mathrm{g}$ isoflavone per g dry weight extract ${ }^{-1}$. Samples were treated with $10 \mathrm{mM}$ of SNP for $15 \mathrm{~h}(50$ units $/ 10 \mathrm{~mL})$ and the exudates extracted for $20 \mathrm{~min}$ with $80 \%$ methanol and analyzed by HPLC-DAD-MS. Mean \pm SD of three independent analyses; different letters in the same line are statistically different $(p<0.01)$. 
elicitor agent in the exudates (results not shown).

In general, these results show that exudates from soybean tissues, mainly those of the embrionary axes, demonstrate good yields of aglycones when elicited by SNP.
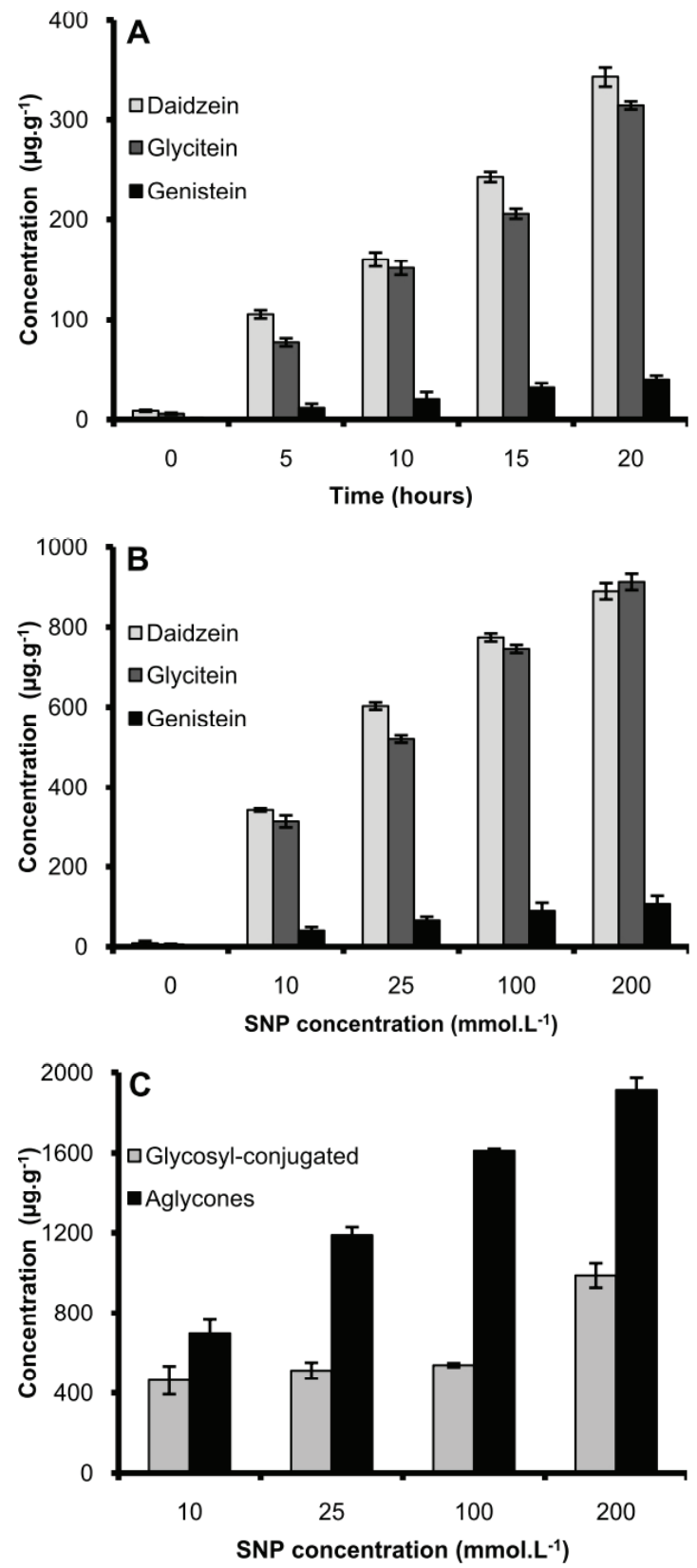

Figure 2. Effect of SNP concentration and time of elicitation in the accumulation of free and conjugated isoflavones. Embrionary axes were treated with SNP $(50$ units $/ 10 \mathrm{~mL})$ and the isoflavones produced determined in the exudates. (A) concentration of aglycones after the indicated periods of elicitation with SNP $10 \mathrm{mmol}^{-\mathrm{L}^{-1}}$; (B) concentration of aglycones and (C) aglycone and glycosyl-conjugates in response to different concentrations of SNP, as indicated, after $20 \mathrm{~h}$ of elicitation. Mean \pm SD of three independent experiments.
Influence of soybean exudates in MCF-7 and $3 T 3$ cells proliferation

The antiproliferative activity of isoflavones has been well documented in various human tumor cell lines (Gacche et al., 2011). As the soybean exudates prepared by elicitation with $100 \mathrm{mmol} . \mathrm{L}^{-1} \mathrm{SNP}$ for $20 \mathrm{~h}$ produced the best response in terms of aglycone forms (Figure 2), their effects on MCF-7 and 3T3 cell lines were evaluated and compared with those of nonelicited extracts.

When MCF-7 cells were exposed to exudates from elicited embrionary axes (Figure 3A) and cotyledons (Figure 3B), a biphasic effect on cell proliferation was observed. The major effect in the cell viability was observed after treating the cells with $500 \mu \mathrm{g} \cdot \mathrm{mL}^{-1}$ of exudates from embrionary axes and cotyledons, which provoked an increase of approximately $20 \%$ of proliferation. When higher concentrations of those exudates were used, a tendency of cell proliferation decrease was observed (Figure $3 \mathrm{~A}$ and $\mathrm{B})$. In contrast, MCF-7 cells exposed to exudates of non-elicited embrionary axes (Figure $3 \mathrm{C}$ ) and cotyledons (Figure 3D) showed a slight dose-dependent viability increase. For both exudates, the maximum observed effect in the viability was around $15 \%$ after exposure of cells to $1000 \mu \mathrm{g} . \mathrm{mL}^{-1}$. These results show that soybean extracts enriched in free isoflavones show a biphasic effect on proliferation of MCF-7 cells. Differently, extracts from non-elicited tissues, which have low concentrations of aglycone isoflavones generally displayed a slightly effect on cell proliferation. Thus, the difference of action in cell viability between non-elicited and elicited exudates may be related to the content of free isoflavone aglycones.

Since MCF-7 cell line expresses estradiol receptor (Saceda et al 1988) it could explain the higher proliferation capacity of this cell towards lower isoflavones concentration. The proliferative effect of flavonoids has been attributed to isoflavones, especially genistein. This isoflavone is able to bind to the estrogen receptor, due to its structural similarity with estradiol, and promote cell growth (Wang et al., 1996). Exudates from elicited embrionary axes presented higher amounts of daidzein and glycitein that have lower estrogenic activity while those from elicited cotyledons presented higher content of the more potent genistein, what may explain their similar effectiveness towards MCF-7 cell proliferation.

The proliferative action of isoflavones was reported in low concentration of estradiol (Casanova et al. 1999). However, it has been reported their antiproliferative effect on tumor cells at high concentrations and this action seems to involve a receptor-independent pathway (Gacche et al., 2011). In agreement, mouse fibroblast cells (3T3) treated with exudates of elicited embrionary axes and cotyledons 
did not display an expressive changing in their viability (results not shown).

Emission of NO by $M C F-7$ and $3 T 3$ treated with soybean exudates

NO emission induced by treatment with soybean exudates enriched in isoflavone aglycones was evaluated in MCF-7 and 3T3 cells, since this radical is extensively involved in various cellular signals, including induction of cell death in tumor lines (Olson \& Garbán, 2008).

The modulation of eNOS by estrogen has been demonstrated (Hisamoto \& Bender, 2005). The eNOS is part of a family of enzymes responsible for synthesis of NO through the oxidation of L-arginine to L-citrulline (Pollock et al., 1991).

Figure 4 shows that MCF-7 cells, treated with exudates of elicited embrionary axes and cotyledons for $72 \mathrm{~h}$, displayed emission of NO, which maximum effect observed at concentration of $1000 \mu \mathrm{g} \cdot \mathrm{mL}^{-1}$ exudates (39 and $25 \%$ for embryonic axis-elicited and cotyledonselicited exudates, respectively). Interestingly, treatment of $3 \mathrm{~T} 3$ cells with both exudates up to $1000 \mu \mathrm{g} \cdot \mathrm{mL}^{-1}$ did not induce significant changes in the emission of $\mathrm{NO}$ after $72 \mathrm{~h}$. Accordingly, when MCF-7 cells were treated with exudates elicited up to a concentration of $1000 \mu \mathrm{g} \cdot \mathrm{mL}^{-1}$ and L-NAME, a selective NOS inhibitor (Baylis et al., 1995), the emission of NO was abolished.

Several evidences suggest the importance of $\mathrm{NO}$ in the development and establishment of cancer (Bing et al., 2001). However, other authors have reported that in high concentration NO presents cytotoxic effect and contribute for the reduction of tumor mass (FellyBosco, 1998). Our results are consistent with these observations, since at lower NO emission by tumor MCF-7 cells coincided with the proliferative effect of the exudates. However, when the emission of NO was higher, it was observed a tendency of cell proliferation inhibition. Our data suggest that the biphasic effect of exudates could be, at least in part, due to modulation of eNOS activity in MCF-7 cells.
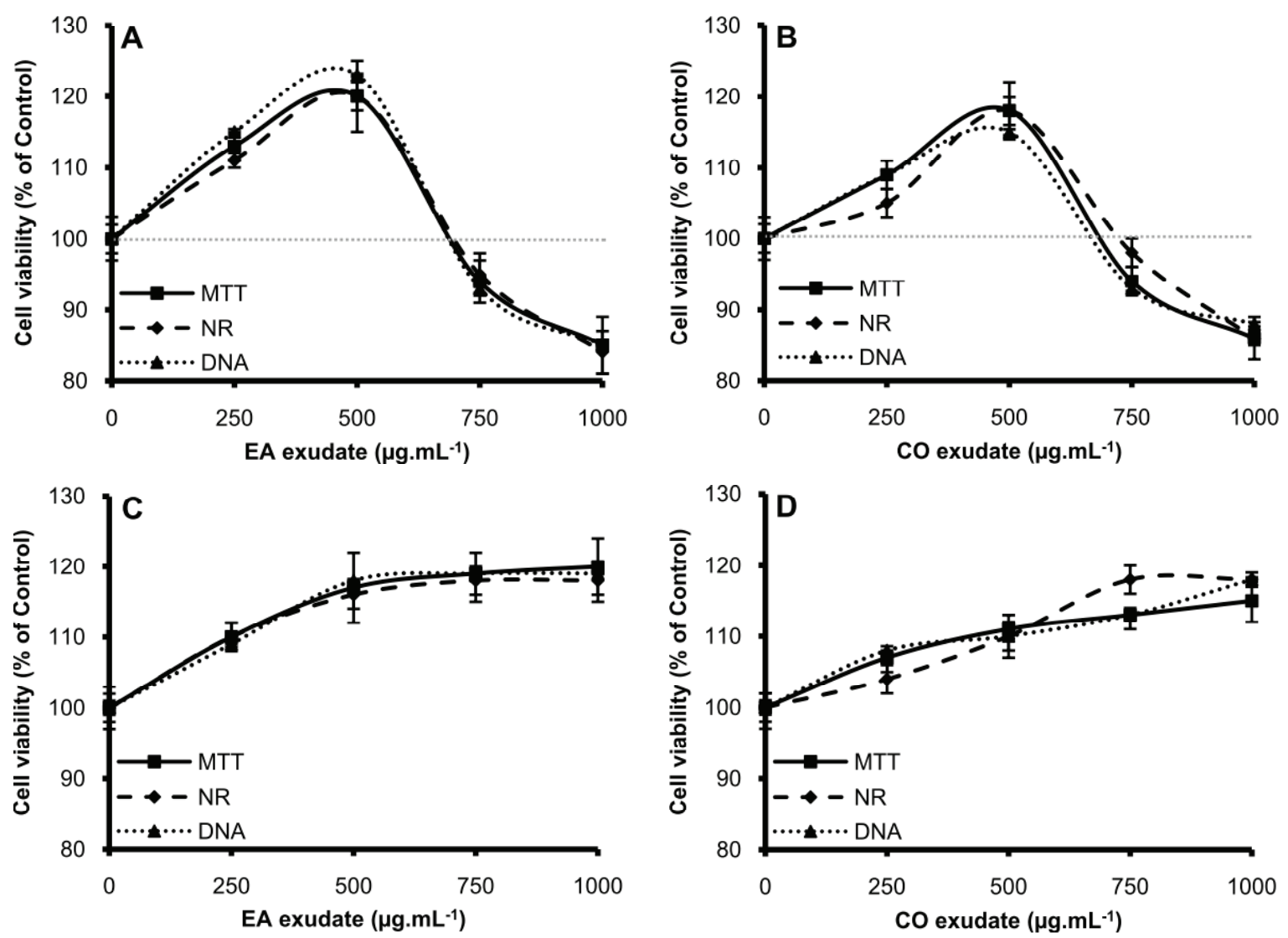

Figure 3. Effects of exudates in natura and elicited with SNP (100 mmol.L-1) on MCF-7 cell viability. A, exudate of elicited embrionary axes (EA); B, exudate of elicited cotyledons (CO); C, exudate EA in natura; D, exudate CO in natura. Cells (10 x $10^{3}$ ) were exposed to different exudates concentrations for $72 \mathrm{~h}$. The results are expressed as percentage of control. Cellular viability was determined by MTT reduction, neutral red uptake (NR) and DNA content assay. Mean \pm SD of three independent experiments. 

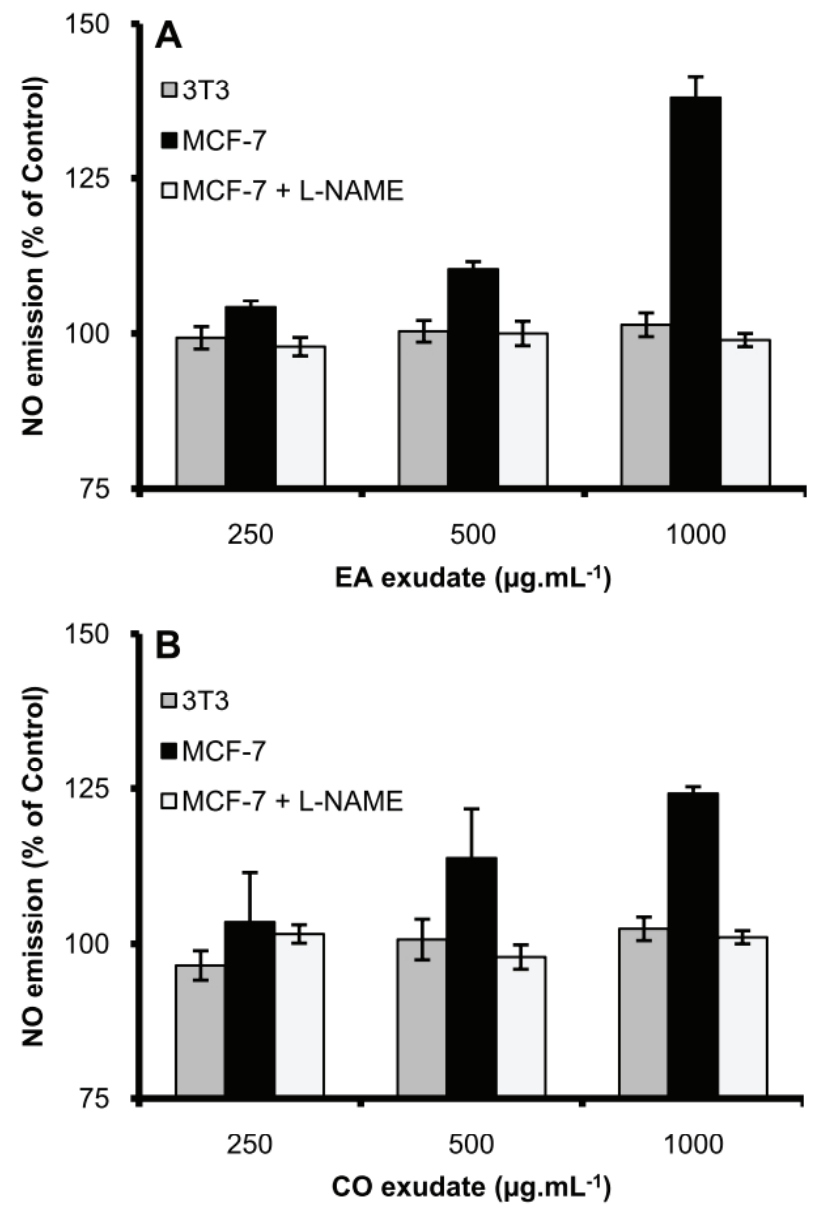

Figure 4. Nitric oxide (NO) emission by $3 \mathrm{~T} 3$ and MCF-7 treated with SNP $100 \mathrm{mmol} . \mathrm{L}^{-1}$ elicited exudates. A, embrionary axes (EA) exudates; B, cotyledons (CO) exudates. Cells $\left(10 \times 10^{3}\right)$ were exposed to different exudates concentrations for $72 \mathrm{~h}$. L-NAME was used at $1 \mathrm{mM}$, where indicated. Mean $\pm \mathrm{SD}$ of three independent experiments.

\section{Conclusion}

The results presented here demonstrate a rapid and easy method to enrich soybean extracts with isoflavones in their bioactive forms, the aglycones. Still, the enriched extracts show biphasic action on the proliferation of breast adenocarcinoma cells with proliferative action at lower concentrations and inhibitory effect at higher concentrations. It is likely that these effects are related to estrogenic activity of free isoflavones and their ability to modulate the activity of eNOS, and thus NO synthesis. Overall, our results suggest that elicitation with SNP could represent a simple method to produce exudates enriched in free isoflavones and could be exploited to produce functional foods or supplements to target health problems.

\section{Acknowledgements}

This work was supported by the FAPESP (grant no. 2008/11636-5). PGF, LF and VVR were supported by a FAPESP scholarship, IS, AZM and CVF are recipients of research fellowship from $\mathrm{CNPq}$.

\section{References}

Adlercreutz H, Mazur W 1997. Phyto-oestrogens and western diseases. Ann Med 29: 95-102.

Baylis C, Masilamini S, Losonczy G, Samsell L, Harton P, Engels K 1995. Blood-pressure (BP) and renal vasoconstrictor responses to acute blockade of nitric oxide:persistence of renal vasoconstriction despite normalization of BP with either verapamil or sodium nitroprusside. J Pharmacol Exp Ther 274: 11351141.

Bing RJ, Miyataka M, Rich KA, Hanson N, Wang X, Slosser HD, Shi R 2001. Nitric oxide, prostanoids cyclooxygenase, and angiogenesis in colon and breast cancer. Clin Cancer Res 7: 3385-3392.

Borenfreund E, Borrero O 1984. In vitro cytotoxicity assays. Potential alternatives to the Draize ocular allergy test. Cell Biol Toxicol. 1: 55-65.

Brouns F 2002. Soya isoflavones: a new and promising ingredient for the health foods sector. Food Res Intern 35: 187-193.

Brown NM, Setchell DR 2001. Animal models impacted by phytoestrogens in commercial chow: implications for pathways influenced by hormones. Lab Invest 81: 735-747.

Casanova M, You L, Gaido KW, Archibeque-Engle S, Janszen DB, Heck HA 1999. Developmental effects of dietary phytoestrogens in Sprague-Dawley rats and interactions of genistein and daiudzein with rat estrogen receptoros alpha and beta in vitro. Toxicol Sci 51: 236-244.

Cingi MR, De Angelis I, Fortunati E, Reggiani D, Bianchi V, Tiozzo R, Zucco F 1991. Choice and standardisation of test protocols in cytotoxicology: a multicenter approach. Toxicol In Vitro 5: 119-125.

Cuyckens F, Claeys M 2004. Mass spectrometry in the structural analysis of flavonoids. J Mass Spectrom 39: $1-15$.

Delledonne M, Xia YJ, Dixon RA, Lamb C 1998. Nitric oxide functions as a signal in plant disease resistance. Nature 394: 585-588.

Dixon RA, Achnine L, Kota P, Liu CJ, Reddy MSS, Wang $\mathrm{L}$ 2002. The phenylpropanoid pathway and plant defence - a genomics perspective. Mol Plant Pathol 3: 371-390.

Felly-Bosco E 1998. Role of nitric oxide in genotoxicity: implication for carcinogenesis. Cancer Metastasis Rev 17: 25-37. 
Gacche RN, Shegokar HD, Gond DS, Yang Z, Jadhav AD 2011. Evaluation of selected flavonoids as antiangiogenic, anticancer, and radical scavenging agents: an experimental and in silico analysis. Cell Biochem Biophys 61: 651-663.

Hamuro M, Polan J, Natarajan M, Mohan S 2002. High glucose induced nuclear factor kappa B mediated inhibition of endothelial cell migration. Atherosclerosis 162: 277-287.

Hisamoto K, Bender JR 2005. Vascular cell signaling by membrane estrogen receptors. Steroids 70: 382-387.

Izumi T, Piskula MK, Osawa S, Obata A, Tobe K, Saito M, Kataoka S, Kubota Y, Kikuchi M 2000. Soy isoflavone aglycones are absorbed faster and in higher amounts than their glucosides in humans. J Nutr. 130: 16951699.

Jenkins DC, Charles IG, Thomsen LL, Moss DW, Holmes LS, Baylis SA, Rhodes P,Westmore K, Emson PC, and Moncada S 1995. Roles of nitric oxide in tumor growth. Proc Natl AcadSci USA. 92: 4392-4396.

Kretzschmar FS, Aidar MP, Salgado I, Braga MR 2009. Elevated $\mathrm{CO}_{2}$ atmosphere enhances production of defense-related flavonoids in soybean elicited with NO and a fungal elicitor. Environ Exp Botany 65: 319-329.

Lin LZ, Harnly JM 2007. A screening method for the identification of glycosylated flavonoids and other phenolic compounds using a standard analytical approach for all plant materials. J Agric Food Chem 55: 1084-1096.

Liu K 1997. Soybeans: chemistry technology and utilization. IPT, New York, p. 82-93.

Messina MJ, Messina V 1991. Increasing use of soyfoods and their potential role in cancer prevention. $J$ Am Diet Assoc 91: 836-840.

Modolo LV, Cunha FQ, Braga MR, Salgado I 2002. Nitric oxide synthase mediated phytoalexin accumulation in soybean cotyledons in response to the Diaporthe phaseolorum f. sp. meridionalis elicitor. Plant Physiol 130: 1288-1297.

Mosmann T 1983. Rapid colorimetric assay for cellular growth and survival: application to proliferation and cytotoxicity assays. J Immunol Methods 65: 55-63.

Olson SY, Garbán HJ 2008. Regulation of apoptosis-related genes by nitric oxide in cancer. Nitric Oxide 19: 170176.

Pilšáková L, Riečanský I, Jagla F 2010. The physiological actions of isoflavone phytoestrogens. Physiol Rev 59:
651-664.

Piskula MK, Yamakoshi J, Iwai Y 1999. Daidzein and genistein but not their glucosides are absorbed from the rat stomach. FEBS Lett 447: 287-291.

Pollock JS, Förstermann U, Mitchell JÁ, Warner TD, Schmidt HH, Nakane M, Murad F 1991. Purification and characterization of particule endothelium-derived relaxing factor synthase from cultured and native bovine aortic endothelial cells. Proc Natl Acad Sci USA 88: 10480-10484.

Saceda M, Lippman ME, Chambon P, Lindsey RL, Ponglikitmongkol M, Puente M, Martin MB 1988. Regulation of the estrogen receptor in MCF-7 cells by estradiol. Mol Endocrinol 2: 1157-62.

Setchell KD, Brown NM, Zimmer-Nechemias L, Brashear WT, Wolfe BE, Kirschner AS, Heubi JE 2002. Evidence for lack of absorption of soy isoflavone glycosides in humans, supporting the crucial role of intestinal metabolism for bioavailability. Am J Clin Nutr 76: 447-453.

Taku K, Melby MK, Nishi N, Omori T, Kurzer MS 2011. Soy isoflavones for osteoporosis: an evidence-based approach. Maturitas 70: 333-338.

Townsend EA, Meuchel LW, Thompson MA, Pabelick CM, Prakash YS 2001. Estrogen increases nitric oxide production in human bronchial epithelium. $J$ Pharmacol Exp Ther 339: 815-824.

Wang TT, Sathyamoorthy N, Phang JM 1996. Molecular effects of genistein on estrogen receptor mediated pathways. Carcinogenesis 17: 271-275.

Yen GC, Lai HH 2003. Inhibition of reactive nitrogen species effects in vitro and in vivo by isoflavones and soybased food extracts. J Agric Food Chem 51: 78927900 .

\section{*Correspondence}

Ione Salgado

Departamento de Biologia Vegetal, Instituto de Biologia, Universidade Estadual de Campinas

Caixa Postal 6109, 13083-970 Campinas-SP, Brazil

ionesm@unicamp.br

Tel. 1935216149

Fax: 1935216149

\#Present address: Departamento de Ciências da Saúde, Universidade Federal de São Paulo, 11060-001 Santos-SP, Brazil 